\title{
Yearning for significance is hard to swallow
}

\author{
Swallow: Foreign Bodies, Their \\ Ingestion, Inspiration, and the \\ Curious Doctor Who Extracted Them \\ Mary Cappello \\ The New Press; 2011
}

$\mathrm{A}$ s I started reading Swallow: Foreign Bodies, Their Ingestion, Inspiration, and the Curious Doctor Who Extracted Them, I wondered why somebody would write such a book. More specifically, I suppose, why would a professor of English at the University of Rhode Island, Mary Cappello, write this book?

The short answer is that she was inspired by a collection of objects that had been ingested or aspirated - and ultimately removed — by the improbably named Chevalier Jackson. The long answer is Swallow itself, a book-length meditation in which Cappello assembles a collage of biography, history, literary criticism, and introspection around her subject.

Cappello is clearly fascinated by Jackson, a laryngologist known as a pioneer in the field of endoscopy in the early part of the 20th century. Although admiring of Jackson the procedural virtuoso - she takes him at his word

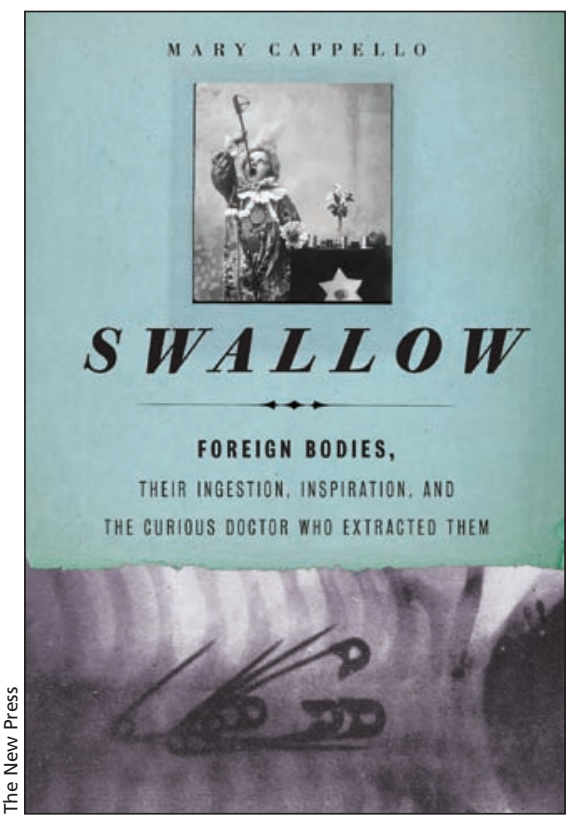

mately sensitive, secretive, and unknowable. This much I learned about Jackson by reading Swallow.

Though I think there is meant to be more to it. But whatever other purpose, loftier or deeper, Cappello may have had in writing this book remains obscure. Like a "hysteric" swallowing a tack, she becomes her own worst enemy.

She is discursive, to say the least, here deconstructing the racism of Jack-

\section{Like a "hysteric" swallowing a tack, the author becomes her own worst enemy.}

when he claims to have never caused an accidental perforation - Cappello is most compelled by Jackson the man: asocial, snobbish, priggish, and Linnaean; a product of post-Civil War America, with all that implies; and ulti- son's time and there, only a few pages later, ruminating on the urge to collect. Meaning is present everywhere, even if Cappello has to manufacture it: "When a woman swallows hardware from a notions counter in the machine age, she announces the store's ordering system as delusional, she makes the immanent but not apparent grand plan of little things in boxes a jumble once again, a primordial mass inside her stomach." This yearning for significance finds its animistic apogee with Cappello's capitalized "aura-laden Things," the objects that Jackson removed from his patients. The effect is a bombardment, from all sides, with postmodern and politically correct double-talk.

Even Cappello's style trips her up. Borrowing an abbreviation that Jackson had used in his notes, she repeatedly refers to foreign bodies as "fbdys", a distracting affectation. Flourishes that are intended to be arty or clever are simply showy — . "... indeed, Idlewood was an idyll for the newly idling classes ..." — or twee — "Is there a word for the pose the boy takes in this photo, fetching as freckles (though he has none)?"

I believe Swallow to be a very personal book: Cappello involves herself in the narrative, first as a child receiving a gastric lavage, then as an adult with her own foreign body, a port through which she will receive chemotherapy. The tragedy of it is that her message remains essentially unsaid because she, as an author, cannot get out of her own way. At her conclusion she contemplates Jackson's coat, and I continue to wonder why.

\section{Paul Moorehead MD}

PhD student

Pathology and Molecular Medicine

Queen's University

Kingston, Ont.

CMAJ 2012. DOI:10.1503/cmaj.111729 